\title{
População de rua e cidade: uma análise da ressignificação dos espaços urbanos
}

\author{
Homeless population and the city: \\ an analysis of the re-signification of urban spaces
}

Lucas Eduardo Lima Dantas [I]

\begin{abstract}
Resumo
As investigações propostas neste artigo pretendem refletir acerca da relação entre a População em Situação de Rua (PSR) e o espaço urbano, levando em consideração as significações e os conflitos produzidos sobre o tecido urbano por esse grupo. Buscar-se-á, portanto, entender a maneira como o indivíduo se relaciona com o espaço através da sua caminhada e das novas significações que produz sobre o ambiente que ocupa. Para entender tal lógica, recorre-se a uma discussão histórica para entendermos o modelo urbano da cidade atual, desde sua disposição espacial ao surgimento de seus problemas sociais.
\end{abstract}

Palavras-chave: população de rua; cotidiano; cidade; urbanidades; imaginário.

\begin{abstract}
The investigations proposed in this article intend to reflect on the relationship between homeless population and urban space, taking into account the meanings and conflicts produced in the urban fabric by this group. Therefore, our aim is to understand the way in which the individual relates to the space through their walk and the new meanings they produce in the environment they occupy. To comprehend this logic, we use a historical discussion to understand the urban model of the present city, from its spatial disposition to the emergence of its social problems.
\end{abstract}

Keywords: homeless people; everyday life; city; urbanity; mental imagery. 


\section{Introdução}

Este artigo tem, como ponto de partida, a necessidade de refletir acerca da relação entre a população de rua e a cidade. Problematizar sua condição sobre o logradouro público, analisar a sua ação nesse território de uso comum. Portanto, está claro, neste estudo, que o espaço urbano e a população de rua estão diretamente relacionados através dos usos que esse grupo faz sobre o espaço para além da sua representação midiática.

A cidade como a concebemos hoje é fruto de uma série de transformações históricas que resultaram em uma produção simbólica dos modelos de sociedade adotados pela civilização ao longo do tempo. Um espaço delimitado pela cultura, pela natureza, pela política, pela economia, enfim: a cidade, grandiosa e sempre em processo de reconstrução, de produção de sentidos e significados a partir do processo de interação social.

As cidades são formações históricas próprias, cada uma com sua individualidade, elas representam a cultura específica de seu tempo, conforme demonstrará de maneira convincente Peter Hall em seu livro Cities in civilization (1988). Hall relembra que hoje as cidades, como centros culturais, econômicos e políticos, podem substituir a realidade do conceito de Nação/Estado. (Freitag, 2012, p. 23)

Podemos entender o atual modelo urbano como o fruto de um processo de ressignificações do modo de habitar, adotado pelas diversas culturas criadas pelo homem vivendo em sociedade. Se hoje residimos em casas e apartamentos e transitamos pelas ruas de maneira organizada, tudo isso se justifica pelo processo de convenção histórica pelo qual passaram os espaços da cidade. Convenção social influenciada, desde os últimos séculos até os dias atuais, por uma corrente urbanística de aspectos racionalistas, em que cada agente social possui sua função e seu espaço muito bem delineado por uma lógica social implícita: onde morar, onde trabalhar, onde transitar a pé ou de carro, onde poder parar e onde apenas prosseguir.

Entretanto, como um contraponto a essa visão, como apresentaremos ao longo desta narrativa, nem tudo e todos estão presos e obrigados a seguir uma lógica pressuposta, desafiando viver a cidade de maneira livre, sem trajetos delimitados ou locais preestabelecidos, tendo seus referenciais construídos pela produção coletiva e guardados na memória do local. Uma produção efervescente, vívida, reinventando o modo de viver e ter direito à cidade.

Com relação a essa memória sobre o passado que constitui a produção sobre o presente da cidade, nesse processo de constante repetição, Michel de Certeau pontua que

As "velhas pedras" renovadas se tornam lugares de trânsito entre fantasmas do passado e os imperativos do presente. São passagens sobre múltiplas fronteiras que separam as épocas, os grupos e as práticas. À maneira das praças públicas para onde afluem diferentes ruas, as construções restauradas constituem, de forma histórica e não mais geográficas, permutadores entre memórias estranhas. (Certeau, 2012, p. 194)

É pelo caminho inverso do racionalismo urbano, pelo viés do "invisível" e do "imprevisível", que levaremos à frente nossas discussões acerca do espaço, muito mais ligado à sua variabilidade de significados 
produzidos e à trajetória própria que cada indivíduo traça para si, reconfigurando as normas desse espaço.

Podemos entender a cidade na contemporaneidade como um espaço que busca cada dia mais fluidez de seus processos, em paralelo à busca pela maior produtividade em menor tempo. Assim como foi a cidade moderna, vista como um espaço de fluidez e velocidade, a cidade agora tem o viés do consumo muito mais acentuado.

Dentro dessa discussão acerca do espaço urbano das cidades, é interessante nos atentarmos para a força invisível, responsável pelas ações e pelos acontecimentos, força esta incessante, que circula sobre todo o espaço e que está presente na prática dos transeuntes urbanos: o cotidiano.

O cotidiano, pode-se afirmar, é aquilo que nos é dado a cada dia, que está presente em nossas rotinas, ações. A força que nos pressiona sobre o espaço e que nos faz chocar sobre os indivíduos por meio das interações e das relações dia após dia. Seria o peso da vida que assumimos sempre ao despertar diário para executarmos os nossos afazeres. Como destaca Certeau, seria também

[...] a dificuldade de viver, ou de viver nesta ou noutra condição, com esta fadiga, com esse desejo. O cotidiano é aquilo que nos prende intimamente, a partir do interior. É uma história a meio-caminho de nós mesmos, quase em retirada, às vezes velada, não se deve esquecer este "mundo memória" segundo a expressão de Peguy. É um mundo que amamos profundamente, memória olfativa, memória dos lugares, memória do corpo, dos gestos da infância, dos prazeres. Talvez não seja inútil sublinhar a importância do domínio desta história "irracional", ou desta "não história", como diz ainda $A$. Dupont, o que interessa ao historiador do cotidiano é o invisível. (Ibid., p. 31)

Como ponto de partida para discussões aqui apresentadas, as relações entre espaço, identidade e memória serão abordadas. 0 modo como o indivíduo se relaciona com a memória urbana contribui também para construir a sua própria identidade - levando em consideração a produção coletiva cumulada pela memória social sobre o espaço habitado -, assim como o imaginário produzido como resultado dessas interações.

Posteriormente, atentar-nos-emos para o papel prático do sujeito dentro da lógica cotidiana. Serão destacados os conceitos desenvolvidos acerca do relato cotidiano, enxergando-o como um elemento de clara importância para a significação desses espaços. Chamando a atenção ao sentido próprio que delimita as relações que venham a ser desenroladas sobre esses locais.

Após essas reflexões sobre o que é esse espaço urbano como modelo de fruição que, ao mesmo tempo, demonstra o deslumbre e o terror do habitar o espaço urbano -, faremos um resgate às suas bases localizadas no século XIX, no qual poderemos encontrar os referenciais para a construção desse moderno que incide hoje sobre o contemporâneo. Investigar acerca da disposição desse espaço, quanto à sua organização urbanística e social, buscando entender as origens de processos como a gentrificação e a segregação dos grupos mais desfavorecidos das áreas mais valorizadas da cidade. Junto a tal investigação, atentar-se-á, também, à formação dos conceitos de público e privado, muito importantes para a compreensão do estabelecimento desse ordenamento urbano. Essas análises 
incorrem sobre o espaço urbano carioca, que possui referências do moderno europeu, com bases francesas.

Concluindo, uma reflexão acerca do papel da população de rua sobre o meio urbano, questionando o seu lugar de enunciação dentro da estrutura social, para buscar entender como o morador de rua se enuncia, ao habitar o espaço público do meio urbano, tendo como resultado disto a construção de uma nova lógica do espaço, um novo mapa "privado" sobre o território habitado. 0 que se buscará demonstrar com tais ponderações é que, apesar de o morador de rua estar submetido a apenas determinados espaços da cidade, os quais, geralmente são os espaços excluídos da convivência comum, são as sobras do urbano, como marquises ou viadutos, silenciados em sua fala, que ele poderá ressignificar como tática cotidiana (Certeau, 2014), a partir de sua presença e de sua prática.

\section{Espaços da cidade, Identidade e Memória: a disposição dos agentes sobre o espaço urbano}

Ambiente de fruição, de trânsito e produção contínua de sentido, o viver na cidade nos dias atuais pode ser entendido como uma experiência antropológica rica e variada. A urbanidade, característica marcante no espaço das cidades, constitui a noção simbólica que os agentes sociais fazem sobre esse território, que são os espaços, sejam eles públicos ou privados.

Refletir sobre a constituição desses espaços é, antes de tudo, atentar-se à produção coletiva dos aspectos identitários e históricos dos indivíduos. Modelo de produção coletiva que se desenrola a partir da prática cotidiana: o habitar, as celebrações, os eventos extraordinários, a rotina, as interações, tudo isso constitui esse panorama urbano que pretendemos aqui abordar. A cidade é o produto da produção constante do cotidiano, e o ato prático de significar os espaços da cidade é também ação identitária que deixa marcas, fica na memória (Pesavento, 2008).

A partir da prática do cotidiano, do que é ordinário, comum, é que as significações sobre os espaços vão sendo concebidas. 0 repertório construído socialmente vai criando novos símbolos e códigos a serem adotados pela sociedade, reformulando o modo de viver sobre e entender as relações que se desenrolam nesse urbano.

De acordo com Pesavento (ibid.), essas significações produzem um território urbano qualificado, sempre em reinvenção, de acordo com os elementos comuns do cotidiano dos indivíduos que participam dessa incessante partilha.

\footnotetext{
Estes espaços, dotados de significado, fazem, de cada cidade, um território urbano qualificado, a integrar esta comunidade simbólica de sentidos, a que se dá o nome de imaginário. Mais do que espaços, ou seja, extensão de superfície, eles são territórios, porque apropriados pelo social. (Ibid., p. 3)
}

A autora chama a atenção para o imaginário, resultado do acúmulo de símbolos, ações e imagens que são produzidos sobre esse meio urbano e usados como referência para as situações ou novos significados que venham a surgir das ações cotidianas. Aqui, especificamente, trata-se acerca do imaginário, visão 
compartilhada dos indivíduos sobre um território específico, tendo como base as relações que ali se desenvolveram ao longo de um período histórico.

Ao entrarmos no campo de discussões sobre o imaginário, é importante destacar opiniões acerca do tema. Maffesoli (2001) trabalha com abordagens a partir da análise das relações cotidianas, formação de uma sociologia do sensível. Dando relevante importância para a experiência do sujeito, o autor destaca as relações de grupo sobre determinado espaço, tendo como base referencial o imaginário coletivo: "O imaginário é algo que ultrapassa o indivíduo, que impregna o coletivo ou, ao menos, parte do coletivo" (ibid., p. 76). Logo, podemos entender imaginário como uma categoria simbólica partilhada e construída socialmente, através dos acontecimentos cotidianos e do substrato produzido pelas relações sociais entre os diferentes grupos.

Maffesoli, apresentando um ponto de ruptura com a definição de alguns outros autores que abordam a temática, defende que, por ser um elemento de construção coletiva, o imaginário não pode ser fragmentado, repartido, levando em consideração os traços culturais e simbólicos de cada sujeito dentro do cerne social.

Pode-se falar em "meu" imaginário ou "teu", mas, quando se examina a situação de quem fala assim, vê-se que o seu imaginário corresponde ao imaginário no qual se encontra inserido. $\mathrm{O}$ imaginário é o estado de espírito de um grupo, de um país, de um estado-nação, de uma comunidade, etc. O imaginário estabelece vínculo. É cimento social. Logo, se o imaginário liga, numa mesma atmosfera, não pode ser individual. (Ibid., p. 76)
Tal conceito é interessante para entender de que forma os grupos sociais se apropriam e ressignificam o espaço urbano através dessa construção que reproduz o que é idealizado na esfera simbólica do imaginário coletivo.

Ainda seguindo as teorias de Maffesoli, Maia (2005) aborda a relação entre imaginário, espaço e a celebração, como realização vívida do espaço a partir da produção histórica relacional dos indivíduos sobre ele. Problematizando sobre as relações nos espaços, Maia discute acerca da "Cidade Partilhada" (p. 77), que seria, em linhas gerais, a realização da aura sobre o espaço através das práticas urbanas.

Como aponta o autor, esse tipo de relação é o que seria a ação geradora do que ele define como "Espaços de Celebração". Na visão dele, "as celebrações podem girar em torno do corpo, do sexo, da imagem, da amizade, da comédia, do esporte, mas o importante é o sentimento de pertença local que se afasta diante de signos globais" (ibid., p. 78). Assim, é visível o apelo para uma visão fenomenológica das relações sociais, na qual a experiência é colocada de maneira destacada dentro da análise.

Pesavento (2008), partindo do mesmo ponto de vista, define tais espaços como os lugares de memória ou lugares de história, pelo sentido de representarem uma ausência que, ao mesmo tempo, se faz presente pela memória, um processo de reconfiguração do tempo sobre o espaço significado.

São representações que dão a ver um "acontecido" que, a rigor, não é mais verificável ou sujeito à repetição. Mas o tempo não é mais irrecuperável, uma vez que, através do imaginário, se faz presente no espírito, dando-se a ler e ver através dos discursos e imagens. (Ibid., p. 4) 
Entende-se que o sentido prático da produção do imaginário coletivo sobre os espaços se dá a partir das relações entre os sujeitos sobre o território em que se constroem novas significações. Dentro dessa perspectiva, Maffesoli afirma que "o mundo é um conjunto de referência que eu partilho com o outro" (Maffesoli apud Maia, 2005, p. 79), assim como também ressalta Certeau, quando defende que o objetivo das relações sobre o espaço é a experiência que esta proporciona: "o trivial não é mais o outro (encarregado de reconhecer a isenção de seu diretor de cena); é a experiência produtora do texto" (Certeau, 2014, p. 158).

É a experiência que o indivíduo acumula que faz com que este seja capaz de produzir as significações sobre o espaço e, consequentemente, contribuir para a formação de uma aura coletiva sobre ele. Locais que possuem essa espécie de aura coletiva em relação a um determinado grupo social são aqueles que Maffesoli caracteriza como os hauts lieux ou altos lugares (Maia, 2005).

Os espaços como os hauts lieux, de acordo com Maia, "são consolidados em diferentes tempos, por "espíritos" diversos que marcaram esse espaço" (ibid., p. 79). Esses espaços possuem características de aglutinação intensa de processos de significação dentro da lógica cotidiana, criando um ciclo sobre o ciclo; o constante ato de produção cotidiana pelos sujeitos durante a história e sobre o espaço chama a atenção dos demais que se interessam pelo lugar, ocupando-o e desencadeando novos outros processos sobre o lugar, construindo, assim, um espaço possuidor de elementos simbólicos e, ao mesmo tempo, constantemente praticado.
Maia cita alguns exemplos de hauts lieux:

No Rio de Janeiro não faltam exemplos de "Hauts Lieux". Podemos listar alguns desses lugares de grande expressão cultural. O imaginário de festa permanente da Lapa, no centro da cidade; a pluralidade e encanto de Copacabana, cantada como "Princesinha do Mar", na zona sul, especialmente na época do final do ano com a grande festa de Reveillon, e também são marcantes os encontros cotidianos das diversas tribos da conhecida praia de Ipanema, por onde circulou a famosa garota que virou musa para a canção traduzida em várias línguas pelo mundo. Esses são pontos de referência não apenas para o carioca, mas para todo o mundo. $O$ que especialmente chama a atenção dos homens para esses lugares? Podemos afirmar que a resposta se concentra na capacidade de aglutinação que esses lugares possuem. Eles têm um certo "espírito" que a todos contamina. (Ibid., p. 79)

Pode-se enxergar, nessa situação, o papel dialético que o indivíduo possui, no momento em que absorve significações do espaço para construção da sua própria identidade, e, no momento posterior, em que usa de tal aparato identitário adquirido para transformar as estruturas simbólicas nele presentes, a partir do processo de ressignificação que produz sobre o espaço.

Podemos entender de maneira mais clara, como essa relação se desenrola a partir da lógica do bairro. Entende-se bairro aqui não apenas como uma delimitação política e geográfica definida por entidades institucionais para a divisão de serviços, mas sim como um objeto simbólico construído socialmente, no qual os indivíduos que o habitam estão 
muito mais ligados por características culturais, identitárias e relacionais (por grau de familiaridade com o espaço e os demais sujeitos que o habitam).

Acerca da noção de bairro, Certeau (2012, p. 39) pontua que "o bairro aparece assim como o lugar onde se manifesta um engajamento social ou, noutros termos: uma arte de conviver com parceiros (vizinhos, comerciantes) que estão ligados a você pelo fato concreto, mas essencial da proximidade e da repetição". Essas duas características citadas pelo autor, proximidade e repetição, podem ser consideradas os dois principais elementos práticos da lógica da vida cotidiana, tendo em vista que a produção dos significados sobre os espaços ocorre a partir de um processo de acumulação histórica, tendo a repetição como a ferramenta que consolida as ideias sobre as ações produtoras diante dos espaços significados.

É, tendo como base a lógica da proximidade, que os indivíduos de determinado local constroem os laços com o ambiente no qual habita, desenvolvendo, assim, uma afetividade mais próxima com determinados locais que não são vistos como lugares de lógica predeterminada e funções delimitadas por um padrão social vigente. Como exemplo, podemos citar a visita de um estrangeiro a uma cidade por ele desconhecida. Ao transitar pela cidade, como um sujeito em processo de acumulação de novos referenciais, ele enxerga a cidade como um objeto físico, desprovido da mesma sensibilidade que um morador, devido a sua relação ainda de distanciamento com o local. Onde este turista vê uma praça, o morador nativo daquele local enxerga, talvez, um ambiente de festa, de discussões, de encontros ou um lugar referenciado por outro local - a praça do mercado do Seu José -, devido à relação entre esses dois espaços.
Todas essas significações se apresentam como resultado da produção coletiva sobre o espaço, no entanto, comportam-se como um conhecimento seleto àqueles que ali residem. O indivíduo que não partilha dessas caraterísticas com o espaço em que transita se comporta como o intruso que não foi convidado para o jantar, em que o prato principal é a memória coletiva produzida - através da repetição e da proximidade - sobre o espaço.

Pollak (1992) trabalha o conceito de memória coletiva, reafirmando esse papel conjunto no qual as identidades individuais são suprimidas por um saber do grupo e as significações não necessariamente estão baseadas na experiência própria, mas sim no acúmulo e na partilha do simbólico.

Em primeiro lugar, são os acontecimentos vividos pessoalmente. Em segundo lugar, são os acontecimentos que eu chamaria de "vividos por tabela", ou seja, acontecimentos vividos pelo grupo ou pela coletividade à qual a pessoa se sente pertencer. São acontecimentos dos quais a pessoa nem sempre participou mas que, no imaginário, tomaram tamanho relevo que, no fim das contas, é quase impossível que ela consiga saber se participou ou não. (Pollak, 1992, p. 201)

É o sujeito de maneira ativa, prática, que constrói o meio à sua volta, faz do espaço reflexo de sua identidade, e vice-versa. Ajusta essas espacialidades às necessidades cotidianas do grupo, e a memória coletiva coloca-se como ferramenta para consolidar todo esse processo. Acerca dessa postura prática do indivíduo sobre a construção de um espaço significado, Certeau (2012) afirma que ele é o responsável principal na construção de "alguns espaços urbanos, da cidadezinha à metrópole, cada um à nossa própria maneira, espaços onde se 
davam os modos de sociabilidade ativa, na família e na escola, no bairro, entre vizinhos ou companheiros de trabalho" (p. 23).

Portanto, a partir das sociabilidades, das enunciações práticas, é que esse indivíduo qualifica os espaços em que vive, transita e produz significados. Mas de que maneira esse sujeito executa tal ação de transformação dessas espacialidades, dessa relação entre o ser e o espaço? Apontando uma perspectiva, poderíamos afirmar que é o relato cotidiano a forma prática adotada pelo indivíduo na produção contínua dessas significações. É esse relato que qualifica, produz memória, poetisa a cidade através da diferenciação dos lugares, refabricando o seu uso, como afirma Certeau (ibid., p. 45) "desmontando as correntes do aparelho urbano".

\section{A retórica urbana como enunciação prática}

Ocupar o espaço também pode ser visto como uma forma de enunciação e até de construção da identidade social de um indivíduo. 0 caminhar pelo mapa urbano constrói um texto que pode ser lido de outra maneira, e que se faz necessário para entender o discurso daqueles que fazem, desse paradigma, a sua própria retórica.

Conforme afirma Certeau (2014, p. 189), "os relatos cotidianos contam aquilo que, apesar de tudo, se pode aí fabricar e fazer. São leituras do espaço". O autor trabalha a partir da valorização do ato de caminhar sobre o mapa da cidade como elemento definidor de um discurso legítimo do ser. Acerca do conceito de cidade, ele define que
"A cidade", à maneira de um nome próprio, oferece assim a capacidade de conceber e construir o espaço a partir de um número finito de propriedades estáveis, isoláveis e articuladas umas sobre as outras. Nesse lugar organizado por operações "especulativas" e classificatórias, combinam-se gestão e eliminação. De um lado, existem uma diferenciação e uma redistribuição das partes em função da cidade, graças a inversões, deslocamentos, acúmulos, etc.; de outro lado, rejeita-se tudo aquilo que não é tratável e constitui, portanto, os "detritos" de uma administração funcionalista (anormalidade, desvio, doença, morte). (Ibid., pp. 160-161)

Partindo desses pressupostos, interessante analisar a forma como esse indivíduo atribui significações aos objetos e aos locais dispostos sobre o espaço urbano, como também a forma como ele transita sobre a estrutura da cidade e, a partir daí, observar as relações que ele tece com os demais agentes sobre esse ambiente, legitimando-o.

A cidade é consumida pelos indivíduos através das significações que se engendram dentro de sua esfera social. A respeito de como as formas de uso compõem a construção de um texto urbano, Certeau explica que:

Mais embaixo (down), a partir dos limiares de onde cessa a visibilidade, vivem os praticantes ordinários da cidade. Forma elementar dessa experiência, eles são caminhantes, pedestres, wandersmänner, cujo corpo obedece aos cheios e vazios de um "texto" urbano que escrevem sem poder lê-lo. [...] As redes dessas escrituras avançando e entrecruzando-se compõem uma história múltipla, sem autor nem espectador, formada em fragmentos de trajetórias e em alterações, de espaços: com relação 
às representações, ela permanece cotidianamente, indefinidamente, outra. (Ibid., p. 159)

É, a partir do relato, que o simbólico circula pelo espaço, a partir das experiências vívidas pelos sujeitos, das experiências compartilhadas entre os indivíduos que ocupam o mesmo espaço e tecem relações. 0 relato comporta-se como um transporte de significados que vão orientando as cargas simbólicas presentes no meio urbano através da atividade cotidiana da cidade. Ir ao trabalho, visitar o teatro, presenciar um acidente em determinado local, ouvir lendas urbanas. Todos esses exemplos são os elementos que constituem a frivolidade dos relatos, que se recriam todos os dias a partir da interação entre sujeitos, espaços e acontecimento cotidianos. Certeau pontua tal questão, fazendo uma analogia com a nomenclatura grega para transporte coletivo, o metaphorai:

Na Atenas contemporânea, os transportes coletivos se chamam metaphorai. Para ir para o trabalho ou voltar para casa, toma-se uma "metáfora" - um ônibus ou um trem. Os relatos poderiam ter igualmente esse belo nome: todo dia eles atravessam e organizam lugares; eles os selecionam e os reúnem num só conjunto; deles fazem frases e itinerários. São percursos de espaço. (Ibid., p. 182)

Ou seja, o ato de relatar o cotidiano comporta-se como a experiência de uma viagem sobre o tempo de maneira simbólica, revivendo momentos a partir de seu efeito simbólico produtor de memória. Os relatos organizam o urbano, constroem a cotidianidade: relatos de crime ou de festas, relatos preconceituosos ou de ativistas, lendas das ruas, contos fantásticos de subúrbios, todos eles se encontram inseridos como objetos de uma gestão democrática da credibilidade urbana.

O relato organiza, portanto, o espaço em que é enunciado. Uma operação metalinguística da prática cotidiana. 0 exercício da oralidade sobre a atitude do viver. A partir desse ato de partilhar com o outro o que foi experienciado, ocorre o processo de ressignificar lugares, criar aura, traçar uma linha transversal sobre a lógica do espaço-tempo. Certeau destaca, ainda, o relato como o espírito vivo da cidade, ativo, aquilo que a mantem viva a partir do exercício do cotidiano. Segundo o autor, "uma cidade respira quando nela existem lugares de palavra, pouco importa sua função oficial - o café da esquina, a praça do mercado, a fila de espera nos correios, a banca do jornaleiro, o portão da escola na hora da saída" (Certeau, 2012, p. 338).

Portanto, observemos os usos e as significações produzidos sobre a População em Situação de Rua sobre a cidade. Esse grupo que, apesar de possuir uma enunciação estruturada, expõe sua identidade, sua visão e seus pensamentos através das caminhadas que realizam sobre o ambiente público. A população de rua atribui à rua não somente um valor de transição de espaço, adiciona, nela, o sentido de produção de sentidos, de habitat. Desconstrói a ideia de rua enquanto limbo público entre os espaços comuns de ocupação, como os ambientes de trabalho e familiar. É, partindo da prerrogativa do ato de escrever com o corpo em movimento, que a PSR faz da rua um lugar de histórias. Histórias estas não só contadas pela linguagem, mas pelas significações e pelo espaço. 0 ato de ocupar e transitar é, nessa lógica, uma forma de contar uma história e de escrever a própria retórica. 
Na rua, não se busca escutar relatos a partir do outro, a retórica do caminhar consiste em praticar o relato contínuo, a vivência dos acontecimentos em primeira pessoa. "O trivial não é mais o outro (encarregado de reconhecer a isenção de seu diretor de cena); é a experiência produtora do texto" (Certeau, 2014, p. 158).

Esse conjunto de ações e práticas demonstra, segundo Certeau, um novo paradigma para entender a lógica social e a cidade em si. Talvez possamos afirmar que essa visão sobre a cidade está a ser de certa maneira executada pelos moradores de rua. Seria, um olhar totalizador sobre o ambiente urbano.

Escapando às totalizações imaginárias do olhar, existe uma estranheza do cotidiano que não vem à superfície, ou cuja superfície é somente o limite avançado, um limite que se destaca sobre o invisível. Nesse conjunto, eu gostaria de detectar práticas estranhas ao espaço "geométrico" ou "geográfico" das construções visuais, panóptica ou teóricas. Essas práticas do espaço remetem a uma forma específica de "operações" ("maneiras de fazer"), a "uma outra espacialidade" (uma experiência "antropológica", poética, mítica do espaço) e a uma mobilidade opaca e cega da cidade habitada. Uma cidade transumante, ou metafórica, insinua-se assim no texto claro da cidade planejada e visível. (Ibid., p. 159)

Pode-se compreender a cidade como o todo do corpo social, constituído pelas estruturas, códigos, processos e agentes que nela subsistem. Enxergando de tal maneira, a retórica do espaço comporta-se como a ferramenta que os agentes sociais utilizam para manter o fluxo produtor de significações e construção de identidades sobre o plano. Sobre o ato de caminhar em relação a essa relação de fluidez, Certeau explica que

\begin{abstract}
$\mathrm{O}$ ato de caminhar está para o sistema urbano como a enunciação (o speech act) está para a língua ou para os enunciados proferidos. Vendo a coisa no nível mais elementar, ela tem com efeito uma tríplice função "enunciativa": é um processo de apropriação do sistema topográfico pelo pedestre (assim como o locutor se apropria e assume a língua); é uma realização espacial do lugar (assim como o ato de palavra é uma realização, sonora da língua); enfim, implica relações entre posições diferenciadas, ou seja, "contratos" pragmáticos sob a forma de movimentos (assim como a enunciação verbal é "alocução", "coloca o outro em face" do locutor e põe em jogo contratos entre locutores). $\mathrm{O}$ ato de caminhar parece, portanto, encontrar uma primeira definição como espaço de enunciação. (Ibid., p. 164)
\end{abstract}

Logo, o relato apresenta-se como instrumento mais importante dentro desse processo de enunciação prática. Seria, pois, a ponte de ligação entre as experiências vividas através dos processos retóricos topográficos e a linguagem discursiva. 0 relato do morador de rua coloca-se como adereço do seu discurso itinerante, simbolizado pelo ato de caminhar. A ferramenta do relato coloca-se como objeto construtor da geografia das ações, e também como via de exposição do genuíno discurso da PSR.

Interessante notar que a construção desse processo de enunciação, do relato, faz-se também pelo agrupamento de símbolos obtidos dentro do processo de interação social. Constrói-se a partir de experiência, relação e observações feitas durante as caminhadas. 
Os símbolos são instrumentos por excelência da "interação social": enquanto instrumentos de conhecimento e de comunicação (cf. a análise durkeimiana da festa), eles tornam possível o consensus acerca do sentido do mundo social. (Bourdieu, 2011, p. 10)

Importante ressaltar a relevância que o relato puro, fruto da retórica caminhatória tem para entendermos a realidade da População em Situação de Rua. Partindo dessa narrativa, que inexiste em qualquer outra esfera maior, como a midiática e a governamental, é que se pode entender a verdadeira realidade da População em situação de Rua e suas verdadeiras enunciações, discursos e visões (sobre si, sobre a sociedade e sobre o espaço). Conforme afirma Certeau, os relatos são aventuras narradas, que

[...] ao mesmo tempo produzem geografias de ações e derivam para os lugares comuns de uma ordem, não constituem somente um "suplemento" aos enunciados pedestres e às retóricas caminhatórias. Não se contentam em deslocá-los e transpô-los para o campo da linguagem. De fato, organizam as caminhadas. Fazem a viagem, antes ou enquanto os pés executam. (Ibid., p. 183)

Entender o relato e sua significância é compreender a ponte entre os discursos, as enunciações, as caminhadas e a realidade objetivada. O discurso coloca-se nesta lógica, como algo transversal, que perpassa pelos diversos campos, remodelando-se, que se encontra em um patamar diferente, desde a linguagem, até chegar nas "artes do fazer".

A partir desses relatos e discursos é que são construídos os "lugares de reconhecimento" (Certeau, 2012) ou "lugares de memória"
(Pollak, 1992). O relato organiza a cidade a partir de sua construção simbólica sobre os espaços. Diferencia, segundo Certeau, espaços de lugares. Ou, sendo mais amplo, no sentido dado ao urbano, Augé (1997, p. 170) afirma que a cidade não passa de "uma combinação de lugares".

Sobre essa relação traçada pelos cidadãos da cidade com esse espaço, é interessante atentarmos para as definições propostas por Augé e Certeau acerca da significação e atribuição de sentido simbólico aos espaços. Augé (1997), que trabalha com a relação "lugar" e "não lugar", define inicialmente a ideia de "lugar" partindo de argumentos que ressaltam o caráter identitário, relacional e histórico que se produz sobre determinado espaço.

A esfera do identitário à qual o autor se refere diz respeito à maneira como o indivíduo constrói sua bagagem sociocultural como ferramenta de reconhecimento, de raízes que tal indivíduo possua para com aquele local. No entanto, o entendimento dessa relação só se faz possível a partir da inclusão das demais esferas simbólicas, o relacional e o histórico, que virão a abarcar as demais características ligadas às relações sociais tecidas pelo indivíduo como forma de interação social, tendo o elemento histórico como norteador de toda a aura produzida sobre aquele espaço. É referencial, logo que no momento em que as relações que continuam a se desenrolar sobre aquele espectro provocam, subjetivamente, um curto-circuito sobre o tempo e o espaço, fazendo com que passado e presente se encontrem através do simbólico contido nas relações. Discorrendo acerca da definição de "lugar" e "não lugar", o autor explica: 
Por lugar e não lugar designamos, é bom lembrar, ao mesmo tempo, espaços reais e a relação que seus utilizadores mantêm com esses espaços. O lugar será definido com identitário (no momento que um certo número de indivíduos podem se reconhecer nele e definir-se através dele), relacional (no sentido que um certo número de indivíduos, os mesmos, podem ver aí a relação que os une uns aos outros) e histórico (no sentido que os ocupantes do lugar podem encontrar nele os rastros diversos de uma implantação antiga, o sinal de uma filiação) [...] Um espaço no qual nem a identidade, nem a relação, nem a história sejam simbolizadas será recebido como não lugar, mas essa definição pode ser aplicada a um espaço empírico preciso ou à representação que os que lá se encontram fazem desse espaço. O que é um lugar para uns é um não lugar para outros e assim inversamente. (Augé, 1997, p. 169)

A partir dessa perspectiva, podemos concordar com a visão de Certeau acerca do "espaço" e do "lugar", que se assemelha muito com os argumentos de Augé. Certeau trabalha com tal perspectiva definindo "espaço" e "Iugar" como dois locais simbólicos dentro do ambiente urbano construído pela prática dos indivíduos. Segundo Certeau (2014, p. 184),

Um lugar é a ordem segundo a qual se distribuem elementos nas relações de coexistência. Aí se acha, portanto, excluída a possibilidade, para duas coisas, de ocuparem o mesmo lugar. Aí impera a lei do "próprio": os elementos considerados se acham uns ao lado dos outros, cada um situado num lugar "próprio" e distinto que define. Um lugar é, portanto, uma configuração instantânea de posições. Implica uma indicação de estabilidade. [...]. O espaço é um cruzamento de móveis. É de certo modo animado pelo conjunto dos movimentos que aí se desdobram. Espaço é o efeito produzido pelas operações que o orientam, o circunstanciam, o temporalizam e o levam a funcionar em unidade polivalente de programas conflitais [sic] ou de proximidades contratuais.

A diferenciação feita a partir do ordenamento simbólico dos espaços e lugares dispostos sobre a superfície do território da cidade é em que podemos ver, de maneira prática, a distinção que os indivíduos e as comunidades fazem para separar o público do privado, o íntimo do comum, a divergência entre a natureza humana privada, da condição humana de origem pública (Sennett, 2016, p. 17). A PSR, inserida nesse contexto, levando em consideração seu ordenamento singular do espaço, traz a tais conceitos uma releitura. Do modo de habitar, das maneiras de distinção dessas duas categorias simbólicas existentes sobre o espaço urbano. Para o morador de rua, o público e o privado misturam-se sobre um mesmo ambiente, o mesmo podemos dizer acerca do espaço e do lugar sob essa ótica caminhatória. Nesse caso, podemos ainda elencar a questão da segregação social sobre o espaço da cidade do ponto de vista do morador de rua. Pretende-se, assim, dizer que o morador, apesar de estar em ambiente público, nem sempre tem livre acesso a todos os seus "lugares". A organização moderna do espaço urbano, a lógica preconcebida sobre o espaço dita as zonas elitizadas e degradadas da cidade. Lógica esta surgida com a cidade moderna, com o urbanismo funcionalista e, consequentemente, sob forte influência do capitalismo. 


\section{A formação do conceito de urbano}

A cidade, como a conhecemos, tem sua origem recente. A cidade moderna ocidental, ao modo como foi concebida na Europa, principalmente em Paris e Londres, no século XIX, pode ser considerada o modelo embrião de urbanização difundido em vários outros países, com variações dependendo do local e da cultura de onde ela esteja situada. Para respaldar tal afirmação, Henry Lefebvre, em tom crítico, aponta tendencialmente os problemas da cidade grega como projeto impossível de cidade perfeita:

Imaginam a liberdade no séc. XX como a liberdade da cidade grega (singularmente travestida por uma ideologia: apenas a cidade como tal possuía liberdade, e não os grupos e os indivíduos). Portanto, pensam na cidade moderna segundo o modelo de cidade antiga, identificada com a cidade ideal e simultaneamente racional. A Ágora, lugar e símbolo de uma democracia limitada aos cidadãos e que exclui as mulheres, os escravos, os estrangeiros, continua a ser, para uma certa filosofia da cidade, o símbolo da sociedade urbana em geral. (Lefebvre, 2001, p. 47)

No entanto, esse modelo - com relação à disposição do espaço, ao modo como se engendram as relações e a forma como se caracterizam as esferas do público e o privado - popularizado por esse modo de viver londrino ou parisiense diferiu um pouco durante a história da sociedade. Interessante notar a influência que esses dois modelos tiveram sobre a construção e a concepção do espaço urbano carioca, tendo em vista que tais modelos se destacaram como o padrão moderno de cidade.
Partindo para uma simples conceituação sobre esses modelos de cidade, podemos elencar alguns que precederam essa concepção moderna de habitar urbano, e com isso também questionar o seu significado, apelando para a relação dialógica entre público e privado dentre esse cenário. Isso quer dizer que, para compreendermos o significado de urbano, temos de recorrer à maneira como os cidadãos dessas cidades se comportavam e entendiam o público e o privado.

A cidade grega, um dos primeiros modelos de cidade datado pela história, ainda hoje é considerada, em alguns aspectos, um modelo perfeito que deveria ser adotado na sociedade atual. Uma cidade fechada em si mesmo, autossuficiente, com seu próprio código de ética e formulação de leis. A cidade-estado grega, especificamente a Atenas arcaica, tinha sua noção de público definida pela Ágora. Seria esse espaço o local de discussão, socialização e realização da cidadania dos indivíduos da cidade, indivíduos estes que fossem considerados cidadãos, claro. Era a Ágora, o local das decisões sobre os temas voltados à cidade e seus cidadãos, onde os códigos de conduta eram escritos de acordo com o modo de interação dos agentes sociais entre si e o espaço urbano. A base da cidade era a democracia direta da Ágora. No entanto, Sennett (2016) vem questionar essa noção democrática da cidade grega, expondo quão segregacionista era a noção de cidadania adotada por essa sociedade.

Embora todos os cidadãos, ricos ou pobres, pudessem frequentar a Ágora, a maioria dos eventos cerimoniais e políticos que ali ocorriam era inacessível à imensa população de escravos e estrangeiros - Metecos - que sustentavam a economia da cidade antiga. [...]. 
Mergulhar diariamente nessa vida intensa e oscilante exigia que se morasse perto. Entretanto uma grande parcela dos membros dessas cidades estado vivia longe, além dos muros, na Khóra; ao fim do século $V$ a.C., cerca de $40 \%$ dos cidadãos residiam a mais de $20 \mathrm{~km}$ do centro, o que significava uma caminhada de, no mínimo, quatro horas pelas estradas da menosprezada região rural, desniveladas e cheias de buracos. (Sennett, 2003, pp. 47-48)

Apesar do caráter especial para frequentar o ambiente da Ágora, foi surgindo, a partir desse contexto de relacionamento social, uma diferenciação entre o modo de habitar o espaço público e o modo de vida privado. 0 laço com o outro não pertencente ao grupo da família, e o compartilhamento de espaços fez surgir o que Sennett caracteriza como res publica, o bem público, sem dono e de todos ao mesmo tempo. 0 autor explica que

Uma res publica representa, em geral, aqueles vínculos de associação e de compromisso mútuo que existem entre pessoas que não estão unidas por laços de família ou de associação intima, e o vínculo de uma multidão de um "povo", de uma sociedade organizada, mais do que vínculo de família ou de amizade. Como na época romana, a participação na res publica é hoje, na maioria das vezes, uma questão de acordo. (Sennett, 2016, p. 16)

Em meados do século XVII, no período que antecede à modernidade, a posição entre público e privado é desenvolvida, sendo vista como aquilo que está aberto à observação de qualquer pessoa. 0 privado, por sua vez, vinha a simbolizar a região protegida da vida pública, definida pelos laços afetivos.
Dessa maneira, "público" veio a significar uma vida que se passa fora da vida da família e dos amigos íntimos; na região pública, grupos sociais complexos e díspares teriam de entrar em contato inelutavelmente. E o centro dessa vida pública era a capital. (Ibid., p. 35)

O que se poder afirmar é que esse tipo de diferenciação entre essas duas categorias espaciais e simbólicas era não somente definido pelas relações, mas também pela atribuição de valor que os indivíduos executavam sobre o espaço da cidade, seja ele público ou privado. De acordo com Sennett, o domínio privado era o ponto demarcador para essa noção entre as duas categorias. 0 autor ainda apresenta uma relação de natureza e cultura, tendo o público como uma construção cultural coletiva (como os códigos da Ágora na Grécia antiga) e o privado como espaço reservado à natureza humana dos sentimentos e das ações primitivas.

Em uma breve analogia, pode-se considerar que o ambiente público era a criação humana, enquanto o privado, a expressão da condição humana. Levando em consideração a criação coletiva qual foi caracterizado o ambiente público, interessante notar como as definições de espaço urbano são por eles em parte delimitadas.

A cidade moderna, concebida como local de interação e fruição das relações públicas, é moldada a partir das noções acerca de sua "urbanidade", que levaria em consideração não somente sua disposição arquitetônica sobre o espaço, como também todo o caráter simbólico atrelado a si, construído pelas relações que ali se dão e pelo processo histórico. No entanto, no limiar da cidade moderna, correntes filosóficas, como o racionalismo, ganharam espaço sobre as questões urbanas, influenciadas 
não somente pelo processo de crescimento populacional da cidade, mas principalmente pelo início do processo de industrialização, com o advento da revolução industrial e o crescimento do capitalismo enquanto sistema financeiro e político.

A construção de uma cidade de espaços delimitados, usos e necessidades definidos foi, talvez, a marca do início desse processo. Como consequência, o viés simbólico foi reduzido aos espaços privados ou aos espaços públicos nos quais era permitido (museus, teatros, praças...). O filósofo francês Lefebvre destaca que essa ideologia urbanista

[...] recebeu formulações cada vez mais precisas, estudar os problemas de circulação, de transmissão de ordens e informações na grande cidade moderna leva ao conhecimento reais e a técnicas de aplicação. Declarar que a cidade se define como rede de circulação e de consumo, como centro de informações e de decisões, é uma ideologia absoluta; essa ideologia, que procede de uma redução-extrapolação particularmente arbitrária e perigosa, se oferece como verdade total e dogma, utilizando meios terroristas. Leva ao urbanismo dos canos, da limpeza pública, dos mediadores, que se pretende impor em nome da ciência e do rigor científico. (Lefebvre, 2001, p. 48)

A crítica do autor coloca-se como pertinente dentro da lógica produtivista, na qual o capitalismo tenta se impor a partir desse processo de industrialização do qual se erige a cidade moderna. Um urbano reduzido ao seu território, desprovido de sentido e alma, visto como espaço vazio de sentido. Sennett (2016) apresenta sua crítica a essa visão de urbano, entendendo esse processo como o contingenciamento do espaço à custa do movimento. 0 autor defende que essa característica da cidade moderna do início do século XIX permeia até os dias atuais. Ele afirma que, dentro dessa perspectiva, "o espaço público se tornou uma derivação do movimento" (ibid., p. 30).

Para entendermos tal questão apontada pelo autor, basta refletirmos acerca da relação do automóvel particular sobre o espaço urbano da cidade. 0 carro particular é visto como instrumento de transição entre os espaços privados e reduz assim, como foi dito, a significação do ambiente urbano público, para simples canais de circulação e fluxo. Expõe, assim como apontou Lefebvre, o caráter racionalista como esse conceito de espaço moderno foi concebido. Ideias que determinam ou buscam determinar o tipo de relação que o cidadão urbano deve construir com o seu habitat, com a cidade. 0 exemplo da rua ilustra bem tal relação: é entendida, por esse urbanismo racional, como espaço de fluxo, no qual pedestres e carros têm seus lugares demarcados além de sentidos predeterminados. A tentativa de transpor tal lógica resulta em acontecimentos considerados disfunções. Sejam acidentes de trânsito, esbarrões nas calçadas, ou, de forma mais profunda, a negação do conceito através do ato de residir sobre o local. A lógica funcionalista desconsidera a produção desses espaços de passagem, negam sua identidade. O que há, na verdade, é a negação parcial do caráter urbano do espaço público, que tem a hipervalorizarão dos espaços privados como consequência desse reducionismo.

O que fica claro dentro de todo esse processo de significação do urbano é a influência que o capitalismo industrial possui sobre a formulação do simbólico da cidade e que, em parte, este exerce influência sobre o cotidiano dos 
cidadãos. Portanto, entende-se a industrialização como fator modelador das definições e dos caminhos como a cidade moderna veio a construir e seu auge. Como afirma Lefebvre (2001, p. 95), "a industrialização fornece o ponto de partida da reflexão sobre nossa época".

A modernidade, como escreveu Baudelaire em The painter of modern life (1863), "é o fugidio, o contingente; é uma metade arte, sendo a outra eterna e imutável (Baudelaire apud Harvey, 2014, p. 21). É nesse contexto do surgimento de novos modelos sociais que o espaço e os indivíduos vão se reformulando diante da nova era moderna que se encontrava o século XIX. O remodelamento das cidades, o desenvolvimento da comunicação, em específico o fortalecimento da publicidade, que crescia de maneira desregulada e insana.

0 processo de industrialização desencadeado pela primeira revolução industrial culminou no crescimento das cidades, do ponto de vista populacional e urbano. A modernidade dá uma nova cara à cidade, cria a metrópole. 0 espaço urbano vê-se tangenciado e concebido, agora mais do que nunca, em função do desenvolvimento industrial. De acordo com Lefebvre,

Para apresentar e expor a "problemática urbana", impõe-se um ponto de partida: o processo de industrialização. Sem possibilidade de contestação, esse processo é, há um século e meio, o motor das transformações da sociedade. Se distinguirmos o indutor e o induzido, pode-se dizer que o processo de industrialização é o indutor e que se pode contar entre os induzidos os problemas relativos ao crescimento e à planificação, as questões referentes à cidade e ao desenvolvimento da realidade urbana, sem omitir a crescente importância dos lazeres e das questões relativas à "cultura". (Lefebvre, 2001, p. 11)

Logo, podemos afirmar que o crescimento dessa cidade, suas atribuições, é em parte um reflexo das necessidades causadas pela indústria sobre esse novo modo de viver. Para Lefebvre, essa relação traçada com a cidade pela indústria não passa de um processo de exploração em vista da produção, danoso ao desenvolvimento urbano no que tange ao fortalecimento do simbólico sobre o espaço.

Ela [a indústria] ataca também a cidade (cada cidade), assalta-a, toma-a, assola-a. Tende a romper os antigos núcleos, apoderando-se destes, o que não impede a extensão do fenômeno urbano, cidade e aglomerações, cidades operárias, subúrbios (com a anexação de favelas lá onde a industrialização não consegue ocupar e fixar a mão de obra disponível). (Ibid., p. 16)

Através do processo de exploração da cidade, percebe-se como se engendram as ações de tangenciamento do espaço, e, como resultado, o apagamento dos traços identitários que os cidadãos pudessem vir a construir sobre o lugar como uma forma de identificação, de construção identitária. A respeito do processo de desenvolvimento das cidades, tendo em vista o urbanismo racionalista e o capitalismo do modelo econômico, o autor exemplifica cidades que surgiram de tal forma e destaca que países onde a formação de cidades se deu por uma outra lógica e que acabaram esbarrando na dependência dos "polos de crescimento". 
Na França, seria possível citar inúmeras cidades submersas pela industrialização: Grenoble, Dunquerque, etc., em outros casos, há uma ampliação maciça da cidade e uma urbanização (no sentido amplo do termo) com pouca industrialização. Este seria o caso de Toulouse. Este é o caso em geral das cidades da América do Sul e da África, cidades cercadas por uma vizinhança de favelas. Nessas regiões e países, as antigas estruturas se dissolvem; camponeses sem posses ou arruinados afluem para as cidades a fim de nelas encontrar trabalho e subsistência. Ora esses camponeses vêm de explorações destinadas a desaparecer pelo jogo dos preços mundiais, o qual depende estreitamente dos países e dos "polos de crescimento" industriais. Esses fenômenos dependem ainda da industrialização. (Lefebvre, 2001, pp. 17-18)

O papel do capital financeiro sobre a construção desse espaço urbano é claro, e, desde aqui, na cidade moderna, já podemos entender isto como um processo de disputa pelo imaginário e memória da cidade, pela via financeira, através das tentativas de definir o modo de vida urbano. Como o autor vem a postular, tal processo pode ser visto como uma estratégia de classe. "A industrialização se comporta como um poder negativo da realidade urbana: o social urbano é negado pelo econômico industrial" (ibid., p. 28).

A escola urbanista de origem francesa, com características marcadas pelo ordenamento do espaço de maneira planejada, simbolizou de modo prático a existência de intenções, por parte tanto do Estado como do poder econômico, em modelar o ambiente urbano sob uma ideologia do capital a partir da lógica racionalista. Os conjuntos habitacionais são a obra-prima dessa ideologia. Aglomerados urbanos similares, caracterizados por setores delimitados a funções específicas. 0 lugar de moradia, do trabalho e do comércio por ramo de atividade, do lazer, etc. As grandes avenidas largas e as praças vazias e amplas também são marca registrada desse modelo. Assim como os lugares são clinicamente demarcados, as atividades dos indivíduos sobre eles também. 0 objetivo desses conjuntos, de acordo com Lefebvre, era de demonstrar a grandeza do capital e a imponência do Estado em se impor sobre o urbano e a cotidianidade dos indivíduos que ali habitavam.

O barão de Haussman, homem deste estado bonapartista que se erige sobre a sociedade a fim de tratá-la clinicamente como o despojo (e não apenas como arena) das lutas pelo poder, substitui as ruas tortuosas, mas vivas, por longas avenidas, os bairros sórdidos, mas animados, por bairros aburguesados. Se ele abre boulevards, se arranja espaços vazios, não é pela beleza das perspectivas. É para "pentear Paris com as metralhadoras" (Benjamin Peret). O célebre barão não esconde isso. Mais tarde, serão gratos a Haussman por ter aberto Paris à circulação. Essa não era a finalidade, o objetivo do "urbanismo" haussmaniano. Os vazios têm sentidos: proclamar alto e forte a glória e o poder do Estado que os arranja, a violência que neles podem se desenrolar. (Ibid., 2001, p. 23)

As praças, nesse novo modelo de urbanização e significação dos espaços, representam o melhor exemplo da violência simbólica executada pelo Estado contra a produção da memória coletiva sobre o território. Conhecidas como lugar de fruição, interação e ambiente de atividades múltiplas e não definidas, as praças eram vistas como os corações vivos da cidade. O local onde o habitar urbano e a produção prática da memória eram realizados 
de maneira a reforçar o sensível nas relações e a criar uma aura local vívida. Sennett (2016) aponta as reformulações provocadas por esse urbanismo francês como a justificativa para a expulsão da produção coletiva desse ambiente, que, apesar de público, não deve ser praticado como "lugar".

[...] a praça deveria ser um monumento em si mesmo, com atividades restritas acontecendo em seu meio, atividades constituídas principalmente de passagem e transporte. Acima de tudo, essas praças não foram concebidas tendo em mente uma multidão lenta que se congrega. Hardouin-Mansard lutou, portanto, para eliminar das praças barracas, bandos de acrobatas e outras formas de comércio de rua, bem como procurou manter os cafés em sua volta, mantidos por detrás de portas, e tirou totalmente as estalagens das praças. (Ibid., p. 87)

Com essa nova lógica capitalista empreendida sobre os espaços públicos da cidade, pode-se afirmar que há um processo claro de segregação e gentrificação acontecendo em seu meio. A elitização dos espaços centrais das cidades a partir de uma lógica urbana que preza por afastar a população pobre dos centros, concebidos agora como objetos de contemplação.

Trazendo tal discussão para o Brasil, podemos analisar o caso da cidade do Rio de Janeiro, observando o processo ocorrido com a reurbanização da sua região central. Antes de seu processo de valorização e consequente elitização, o centro do Rio de Janeiro era, em grande parte, povoado pelos cortiços, locais onde residiam, prioritariamente, pessoas pobres que migraram de outras partes do País, assim como os negros alforriados do processo da escravidão. Cortiço é um aglomerado de pequenas casas em um único terreno e com uma única saída. Uma espécie de vila, entretanto, com uma estrutura precária, às vezes sem luz, esgoto e água. Com o avanço no crescimento das cidades, a população desses locais também aumentava em número.

Seguindo o modelo apontado antes por Lefebvre, em Paris, o prefeito da cidade do Rio, na época, Pereira Passos, iniciou o processo de reformulação das zonas centrais da cidade, através do alargamento das ruas, revitalização e criação de praças, além da modernização dos serviços públicos. Não foi por acaso que sua gestão ficou vulgarmente conhecida como o "bota abaixo", pelo número de prédios destruídos na cidade (Benchimol, 1992).

Com a expulsão dos pobres das áreas que começavam a se tornar valorizadas, esses indivíduos começaram a ser jogados em áreas desinteressantes para a elite: os morros e as saídas das cidades, afastados das luzes e dos lazeres dessa cidade que se remodelava. A população de rua também foi afastada do centro, tendo seus espaços de habitação afastados da cidade. A modernidade, na cidade do Rio de Janeiro, também trouxe consigo a acentuação do processo de segregação e gentrificação sobre o espaço urbano que se configurava (ibid.).

É importante ressaltar que, apesar da cidade moderna, racionalizada em seus espaços, projetada ordenadamente para fazer circular e fluir esse novo grande público que a habita e a faz funcionar como uma engrenagem de produção do mercado capital, escapa ao seu modelo de projeto uma atração que se impõe como espaço de fruição, de significados e subjetividades sobre os muitos novos signos que se espalham no urbano, como carros e trens, intenso tráfego, vitrines e desejos, produtos, mercadorias, pessoas, multidão. 


\section{O habitar público da PSR e a formação de um "mapa privado"}

O mundo contemporâneo que se apresenta à nossa vista é constituído, podemos assim afirmar, por uma liberdade no que tange às relações entre sujeitos, espaços e significados. Tais elementos são construídos de maneira muito mais variável, híbrida. A própria relação do indivíduo com o espaço urbano, na esfera do território ou do simbólico, se dá hoje, a partir da mediação de novos elementos e práticas.

Todos os agentes dispõem de espaços dentro da lógica social. O posicionamento de cada grupo nos sistemas de enunciações denota uma relação de poder entre o grupo que emite enunciação, os demais grupos e agentes da sociedade e a ordem preestabelecida vigorante. Considera-se também, a partir desse pressuposto, que o lugar exerce poder sobre o discurso dito. Tal influência altera a importância e a visibilidade que Ihe são dadas. Como exemplo, podemos dar as diferenciações entra o discurso institucional - dos governantes, autoridades de Estado -, o discurso mediático dos meios de comunicação, o discurso do setor econômico empresarial, o discurso da opinião pública e o discurso de grupos minoritários da sociedade - classes desfavorecidas, movimentos políticos dissidentes de esquerda, grupos étnicos e a própria População em Situação de Rua, que se compõe enquanto possível classe e também pode ser dissolvida nos demais grupos.

Os discursos institucionais podem ser considerados um dos modelos de discurso hegemônico dentro da esfera social. Pode ser analisado, dessa forma, justamente em função dos elementos contidos na sociedade que respaldam sua credibilidade, como a estrutura política de forma mais clara. Logo, enxerga-se, desse modo, a importância que o ambiente em que os discursos são produzidos possui, simbolicamente, sobre esse mecanismo. 0 capital social que ele emana para quem exercita o ato de enunciar.

No caso dos modelos retóricos observados nas esferas mediática, econômica e política, pode-se observar uma não generalização desse setor, logo que eles transitam entre o hegemônico e o contra-hegemônico. A respeito do conceito de hegemonia, Gruppi explica que

Uma classe é hegemônica, dirigente e dominante até o momento em que através de uma classe sua ação política, ideológica, cultural - consegue manter articulado um grupo de forças heterogêneas e impedir que o contraste existente entre tais forças exploda, provocando assim uma crise na ideologia dominante, que leve à recusa de tal ideologia, fato que irá coincidir com a crise política das forças no poder. (Gruppi, 1978, p. 67)

Por fim, os grupos minoritários da sociedade possuem um discurso que não tem a mesma relevância social, política e ideológica devido à sua posição dentro da infraestrutura em questão e, por consequência, do acúmulo de capital social objetivado.

Assim, fica exposta a tentativa de regulação dos discursos emitidos pelos grupos sociais. 0 discurso, nessa situação, engendra uma relação de poder, de sobreposição entre os grupos, uma estrutura de disputa simbólica. Acerca do discurso na sociedade, Foucault postula: 
Em toda sociedade a produção do discurso é ao mesmo tempo controlada, selecionada, organizada e redistribuída por certo número de procedimentos que tem por função conjurar seus poderes e perigos, dominar seu acontecimento aleatório, esquivar sua pesada e temível materialidade. (Foucault, 2012, pp. 8-9)

A materialidade colocada por Foucault refere-se à forma como se constroem as relações de poder a partir do discurso. Essa relação de poder baseia-se na interação dos indivíduos com as estruturas simbólicas existentes utilizando a ferramenta do discurso. A PSR em seu discurso poderia dispor de elementos que pudessem alterar sua condição simbólica e talvez, até, social e econômica. Devido a essa regulação do discurso, a sociedade em que estamos inseridos tem como pressuposto tal estrutura e, por conseguinte, os lugares que cada agente deve se colocar.

Outra explicação para o cerceamento do poder de fala dado à PSR seria enxergar o discurso, além de sua função de poder, como instrumento de comunicação para interação social dos indivíduos. Porém, como defende Bourdieu, a relação entre a comunicação e as estruturas estruturantes de poder é inseparável.

Contra toda as formas de erro "interacionista" o qual consiste em reduzir as relações de força a relações de comunicação, não basta notar que as relações de comunicação são, de modo inseparável, sempre, relações de poder que dependem, na forma e no conteúdo, do poder material ou simbólico acumulado pelos agentes (ou pelas instituições) envolvidos nessas relações e que, como um dom ou polatchi, podem permitir acumular poder simbólico. (Bourdieu, 2011, p. 11)
Logo, os procedimentos de exclusão também atingem a região dos discursos das minorias, em especifico o da população de rua. $O$ ato de negação do espaço da fala ou da desvalorização, devido à posição de enunciação, caracteriza-se como elemento que reforça as ações ligadas ao processo de exclusão social. Dentre essas ações, podemos elencar como maneiras de interdição do discurso, além da negação da fala, o descrédito da retórica por motivo de loucura ou por elementos que são exteriores à enunciação, mas ainda referentes à condição do indivíduo que produz a narrativa.

Em uma sociedade como a nossa, conhecemos, é certo, procedimentos de exclusão. O mais evidente, o mais familiar também, é a interdição. Sabe-se bem que não se tem o direito de dizer tudo, que não se pode falar de tudo em quaisquer circunstâncias, que qualquer um, enfim, não pode falar de qualquer coisa. (Foucault, 2012, p. 9)

Pode-se entender o discurso da PSR como um discurso interditado, logo que a visibilidade e o respaldo dado a esse grupo são muito pequenos. Exemplo disso são as oportunidades dadas pelos setores, estruturas e alguns agentes sociais. Quando surgem assuntos referentes ao esse grupo, a fala que se enuncia geralmente vem de fora. Seja a mídia falando sobre os moradores de ruas e suas mazelas perante a sociedade, seja o poder público apresentando a PSR como um mal-estar social que deve ser resolvido. Há, ainda, os casos das Organizações Não Governamentais (ONGs) que conduzem ações assistencialistas temporais a esse grupo, como a distribuição de alimentos e roupas. 
Para ilustrarmos os casos de ações assistencialistas executadas pelas ONGs, vejamos a ação da distribuição da famosa sopa para as pessoas que são colocadas como necessitadas: não se pergunta, ao morador, se ele quer aquilo que lhe é distribuído como algo subjetivamente impositivo. Sua condição de suposta miséria denota que ele não possui escolha, sua retórica pouco importa no momento em que não tem outra opção. 0 discurso de optar por algo diferente se invalida, devido à posição em que foi colocado como desfavorecido.

Além dos conceitos já expostos para explicação desse processo de negação do discurso da PSR, podemos apontar a loucura como desvalorização simbólica do que se diz. Conforme Foucault, "O louco é aquele discurso que não pode circular como o dos outros: pode ocorrer que sua palavra seja nula e não seja acolhida, não tendo verdade nem importância" (ibid., p. 10).

A relação que se pode tecer entre o discurso do indivíduo classificado como louco e o discurso do morador de rua se inicia pelas características da desvalorização da enunciação, mas não se reduz a isso. Diante da sociedade atual e dos padrões éticos, morais e sociais estabelecidos, esses dois exemplos se caracterizam como algo que não obedece a essa lógica imposta.

O louco é visto como tal devido à desconexão do que fala e à maneira de agir perante a realidade. 0 morador de rua assemelha-se ao modelo de classificação do louco no que se refere ao modo de agir - não tem o agir igual ao de uma pessoa caracterizada louca, mas tem sua conduta analisada como dissonante do da norma social vigente - pois se encaixa nos paradigmas existentes de convívio e vivência coletiva. Logo, constrói sobre si um novo modelo, uma nova "maneira" de se comportar dentro do sistema. Tal iniciativa pode ser caracterizada como uma forma de luta social, de tentativa de empoderamento de seu próprio discurso ou de validação dele. Segundo Foucault, "o discurso não é simplesmente aquilo que traduz as lutas ou os sistemas de dominação, mas aquilo por que, pelo que se luta, o poder do qual queremos nos apoderar" (ibid., p. 10).

Percebe-se que a luta pelo poder dentro do âmbito discursivo é algo latente. Nos casos das minorias privadas de obterem seu próprio discurso, às vezes, elas apoderam-se de discursos externos como se fossem seus, por uma questão de representatividade dentro do sistema social existente. Caracteriza-se como outra vertente além da disputa ideológica pelo empoderamento, de um discurso genuíno que seria a alienação do discurso que o indivíduo enuncia.

Tal questão vista sob o viés da PSR se caracteriza no momento em que o morador, desprovido de discurso próprio a respeito de sua condição, adota as idealizações criadas por outros setores da sociedade para caracterizá-lo. Adota um discurso externo a si para se autodescrever e entender a sua realidade enquanto resguarda a sua retórica discursiva como forma de conservação identitária -, com o objetivo de facilitar sua aceitação perante o contexto social existente, já que o que a enunciação que o indivíduo elucida é considerada, em alguns casos, inválida.

O discurso nada mais é do que a reverberação de uma verdade nascendo diante dos seus próprios olhos; e, quando tudo pode, enfim, tomar a forma do 
discurso, quando tudo pode ser dito, o discurso pode dito a propósito de tudo, isso se dá porque todas as coisas, tendo manifestado e intercambiado seu sentido, podem voltar à interioridade silenciosa da consciência de si. (Ibid., p. 46)

A partir disso, levanta-se a discussão acerca do discurso emitido pela PSR em alguns casos, tentando diferenciar quando o discurso que se pronuncia é próprio ou deslocado, assimilado de outro agente ou estrutura social. Sobre esse modelo de reprodução de ideias enunciativos, Bourdieu postula que

Se as relações de forças objetivas tendem a reproduzir-se nas visões do mundo social que contribuem para a permanência dessas relações, é porque os princípios estruturantes da visão do mundo radicam nas estruturas objetivas do mundo social e porque as relações de força estão sempre presentes nas consciências em forma de categorias de percepção dessas relações. (Bourdieu, 2011, p. 142)

Logo, procurando desviar-se dessa reprodução discursiva que pode vir a acontecer ao que se enuncia pela população de rua, busca-se um outro caminho de entendimento da enunciação, que está mais distante das influências que produzem as estruturas dominantes da sociedade e seus respectivos agentes: o caminhar pela cidade.

As retóricas ambulatórias, como define Michel de Certeau, seriam um outro modo de enunciação dentro do sistema social. Ao autor traça relações entre o espaço e o texto, o movimento e a enunciação. 0 ato de caminhar seria outra forma mais livre de emitir o discurso sobre o espaço, sofrendo menos influências das estruturas dominantes. Certeau define tal pensamento, afirmando que
Existe uma retórica na caminhada. A arte de moldar frases tem como equivalente uma arte de moldar percursos. Tal como a linguagem ordinária, esta arte implica e combina estilos e usos. O estilo especifica "uma estrutura linguística que manifesta no plano simbólico [...] a maneira de ser no mundo fundamental de um homem". Conota um singular. O uso define o fenômeno social pelo qual um sistema de comunicação se manifesta de fato: remete a uma norma. $O$ estilo e o uso visam, ambos, uma "maneira de fazer" (falar, caminhar, etc.), mas como tratamento singular do simbólico, o outro como elemento de um código. Eles se cruzam para formar um estilo do uso, maneira de ser e maneira de fazer. (Certeau, 2014, p. 166)

Logo, para compreender de forma totalizadora o ato enunciativo desses indivíduos, faz-se necessário entender o discurso redigido sobre o espaço em sua forma "ambulatória", através do uso e ocupação que este traça sobre o espaço físico e simbólico.

A caminhada comporta-se não somente como seu discurso prático sobre o território, mas também como a maneira que o indivíduo constrói significações próprias sobre o espaço que ele transita. Atribui significados específicos, baseados em sua experiência com o meio urbano, produzindo uma lógica cotidiana específica. Seria, então, a produção de um mapa mental, que carregaria símbolos e informações colhidas pelo indivíduo a partir de suas vivências práticas com o meio urbano no qual está inserido. Em outras palavras, seria a sua trajetória urbana.

Produtores desconhecidos, poetas de seus negócios, inventores de trilhas na selva da racionalidade funcionalista, os consumidores produzem uma coisa que se assemelha às "linhas de erre" que fala 
Deligny. Traçam "trajetórias" indeterminadas", aparentemente desprovidas de sentido porque não são coerentes com o espaço construído, escrito e pré-fabricado onde se movimentam. São frases imprevisíveis num lugar ordenado pelas técnicas organizadoras de sistemas. (Ibid., p. 91)

O morador de rua, a partir desse processo, transforma tal espaço, ressignifica e cria história sobre ele; sua caminhada escreve, sobre o tecido urbano, a sua identidade que ali vem sendo constituída. Traduziria, talvez, a visão exposta por Simmel acerca do que é o espaço: "O espaço em geral é apenas uma atividade da alma, apenas a maneira humana de unir estímulos sensoriais em si desconexos em visões unitárias" (Simmel, 2013, p. 76).

Um mapa "privado" é concebido a partir do ponto de vista daquele que vive as experiências; o ato de habitar colocado aqui como ferramenta produtora de sentido, singularidade particular do indivíduo, nesse caso, do morador de rua, que transpõe a lógica de habitar e do habitat estabelecida pela ordem social do espaço urbano no qual este se insere.

Interessante perceber a forma como se dão essas práticas para a produção desse novo terreno descrito aqui como um mapa sobre o mapeado espaço urbano. 0 morador de rua age sobre o território do outro, como um modo de viver e sobreviver, criando sua própria lógica. Sua ação, de acordo com Certeau, é a tática cotidiana, a força do oprimido, a astúcia do fraco no local que lhe é externo, que não Ihe é próprio.

[...] chamo de tática a ação calculada que é determinada pela ausência de um próprio. Então nenhuma delimitação de fora Ihe fornece a condição de autonomia. A tática não tem por lugar senão o do outro. E por isso deve jogar com o terreno que lhe é imposto tal como organiza a lei de uma força estranha. Não tem meios para se manter em si mesma, à distância, numa posição recuada, de previsão e de convocação própria: a tática é movimento "dentro do campo de visão do inimigo", como dizia von Bulow, e no espaço por ele controlado. (Certeau, 2014, pp. 94-95)

O sujeito que recorre à tática cotidiana é aquele que é desprovido de poder, tendo suas ações como algo não planejado, espontâneo, sob a forma de resistência à lógica preestabelecida, calculada, estratégica. Em muito se assemelha ao modelo de vida em que se encontra a população de rua, subjugada a viver sob a jurisdição de uma estratégia do Estado, das instituições sociais que, de alguma forma, possuem influência sobre a maneira como esse território é significado. 0 autor pontua que "a tática é determinada pela ausência de poder" (ibid., p. 95), colocando-a em contraposição à estratégia, práticas calculadas exercidas sobre o ambiente pelas esferas de poder social.

Apesar de entendermos esse conjunto de experiências adquiridas pelo indivíduo a respeito do espaço em que se encontra como a formulação de um mapa as partir dessa postura tática, temos de colocar tal elemento como um resultado do processo de interação entre o ser e o ambiente. 0 que se procura expor, a partir de tal afirmação, é o fato de que a produção desse repertório se dá pela ação tática, pela lógica do percurso, apresentada por Certeau (ibid.).

Analogamente, o autor expõe a relação de mapa e percurso como um, o processo prático e o outro, teórico. Como o ver e o fazer, o habitar e o narrar. 0 percurso, no âmbito da análise da população de rua, seria sua maneira 
pura de viver e de se relacionar com o ambiente urbano, enquanto o mapa, a construção sobre a memória adquirida por essas interações sobre o espaço. A particularidade desse habitar faz com que o processo de criação de mapas, através da execução dos percursos, seja fato constituinte da identidade desses indivíduos, que não somente ressignificam o espaço, como também usam esse mesmo espaço para ressignificar a si mesmos.

\section{[I] https://orcid.org/0000-0001-8491-9660}

Universidade Federal Fluminense, Instituto de Ciências Humanas e Filosofia, Programa de Pós-Graduação em Antropologia. Niterói, RJ/Brasil. lucasvlfsa@gmail.com

\section{Referências}

AUGÉ, M. (1997). “Novos mundos". In: AUGÉ, M. Por uma antropologia dos mundos contemporâneos. Paris, Bertrand Brasil.

BENCHIMOL, J. L. (1992). Pereira passos: um haussmann tropical. A renovação urbana na cidade do Rio de Janeiro no início do século XX. Disponível em: <http://www.rio.rj.gov.br/ dlstatic/10112/4204210/4101387/pereira_passos_haussmann_carioca.pdf>. Acesso em: 7 mar 2018.

BOURDIEU, P. (1997). "Efeitos de Lugar". In: BOURDIEU, P. (org.). A miséria do mundo. Petrópolis, Vozes.

(2011). O poder simbólico. Rio de Janeiro, Bertrand Brasil.

CERTEAU, M. de (2012). A invenção do cotidiano: morar, cozinhar. Petrópolis, Vozes. (2014). A invenção do cotidiano: artes do fazer. Petrópolis, Vozes.

FOUCAULT, M. (2012). A ordem do discurso: aula inaugural no Collége de France, pronunciada em 2 de dezembro de 1970. São Paulo, Edições Loyola.

FREITAG, B. (2012). Teorias da cidade. Campinas, Papirus.

GRUPPI, L. (1978). O conceito de hegemonia em Gramsci. Rio de Janeiro, Graal.

HARVEY, D. (2014). "Espaços e tempos individuais na vida social”. In: HARVEY, D. Condição Pós-moderna. São Paulo, Edições Loyola.

LEFEBVRE, H. (2001). O direito à cidade. São Paulo, Centauro. 
MAFFESOLI, M. (2001). O imaginário é uma realidade. Revista Famecos. Porto Alegre, n. 15, pp. 74-82.

MAIA, J. (2005). Michel Maffesoli e a cidade partilhada. Revista Famecos. Porto Alegre, n. 26, pp. 77-85.

PESAVENTO, S. J. (2008). História, memória e centralidade urbana. Revista Mosaico, v. 1, n. 1, pp. 3-12.

POLLAK, M. (1992). Memória e Identidade Social. Estudos históricos. Rio de Janeiro, v. 5. n. 10, pp. 200-212.

SENNETT, R. (2003). Carne e pedra: o corpo e a cidade na civilização ocidental. Rio de Janeiro, Record. (2016). O declínio do homem público: as tiranias da intimidade. Rio de Janeiro, Record.

SIMMEL, G. (2013). Sociologia do espaço. Revista Estudos Avançados. IEA-USP, n. 27, pp. 75-112.

Texto recebido em 6/fev/2019

Texto aprovado em 17/abr/2020 
